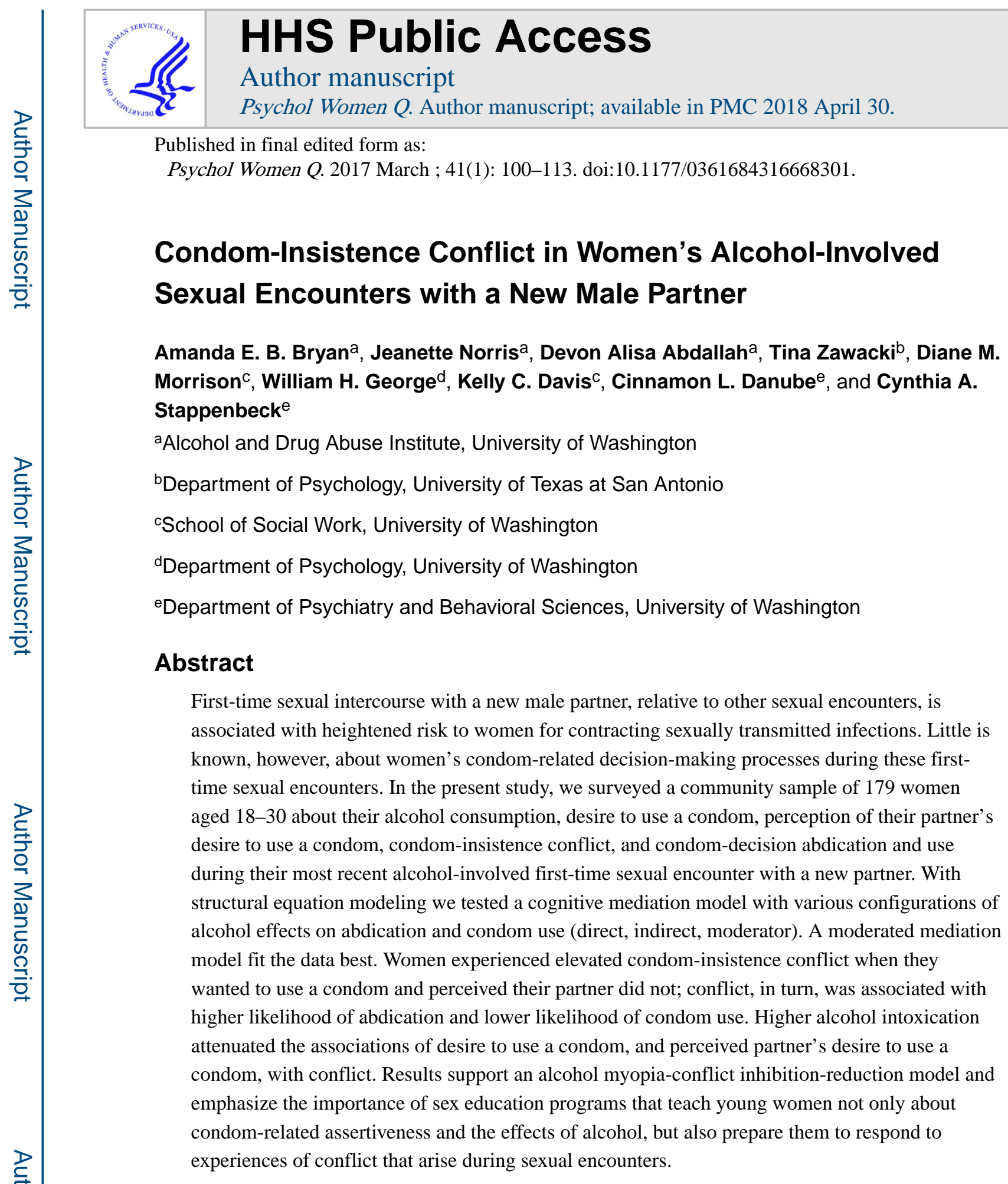

\title{
Keywords
}

condom use; abdication; conflict; alcohol intoxication; moderated mediation

Any inquiries about this research or the data used in it should be directed to Amanda E. B. Bryan, School of Social Work, University of Washington, $410115^{\text {th }}$ Ave. NE, Seattle, WA 98105. Contact: amanda.eb.bryan@gmail.com.

Amanda E. B. Bryan is now at the School of Social Work, University of Washington. 
The male condom is a highly effective means of attenuating health risks associated with heterosexual sexual intercourse, providing protection against pregnancy and sexually transmitted infections (STIs), including HIV/AIDS (Centers for Disease Control and Prevention, 2013). A substantial proportion of young adults, however, report no or inconsistent condom use (Reece et al., 2010; Rhodes, McCoy, Omli, Cohen, Champion, \& Durant, 2007). Understanding how individuals make decisions about condom use, particularly in high-risk sexual situations, is an important precursor to providing effective public education programs that may increase condom use (Norris et al., 2009). In the present study, we employed short-term retrospective surveys to learn about young women's cognitions regarding condom use during high-risk sexual encounters. We then used structural equation modeling to examine condom-related decision-making processes and the moderating effects of contextual factors on these processes.

First-time sex with a new partner (FTNP sex) presents risks that make condom use particularly relevant and important. Although condom use is more common with new or casual sex partners than with regular partners, a substantial number of people report not using condoms with new partners (Hock-Long et al., 2013; Nesoff, Dunkle, \& Lang, 2016; Sanders et al., 2010); for instance, in a nationally-representative U.S. probability sample, $40.7 \%$ of women who recently had a FTNP sexual encounter reported that they had not used a condom (Sanders et al., 2010). New partners are less likely than well-established partners to possess information about each other's sexual histories and risk status upon which to base decisions to use or forego condoms (Lenoir, Adler, Borzekowski, Tschann, \& Ellen, 2006; Niccolai et al., 2004), and lack of awareness about a partner's sex history is associated with STI incidence for people in new sexual partnerships (Drumright, Gorbach, \& Holmes, 2004). Furthermore, FTNP sexual encounters are highly likely to co-occur with alcohol consumption, which may attenuate perceptions of the new partner's "riskiness" (Norris et al., 2013) and narrow attentional focus toward immediate instigatory stimuli (George \& Stoner, 2000; e.g., cognitions that encourage moving forward with sex, such as sexual arousal) and away from higher-level inhibiting cognitions (e.g., about the possible consequences of unprotected sex), a process known as "alcohol myopia" (Steele \& Josephs, 1990). Because there is no prior experience of decision-making about condom-use with a new partner, FTNP sexual encounters are particularly informative for researchers who seek to understand condom-related decision-making processes. To date, however, decisionmaking processes about condom use in FTNP sexual encounters have been infrequently examined in empirical research.

Although both partners have the potential to influence whether a condom is used in a particular sexual encounter, we focused on the female partner's decision-making processes in heterosexual encounters for two reasons. First, the risks associated with heterosexual FTNP sex are disproportionately borne by women because they have the potential to become pregnant and they are more susceptible than men to some STIs (Centers for Disease Control and Prevention, 2014); indeed, acquiring a new sex partner confers increased risk to young women for contracting an STI (Winer et al., 2003). Second, because men are the condom wearers, women are faced with negotiating condom use and deciding how to respond if partners' wishes differ from their own (e.g., abdicate to partners' wishes, refuse to have sex; Amaro, 1995; Harvey et al., 2006). These decisions may be especially challenging in 
encounters with new partners, whose wishes about condom use and likely responses to condom requests and negotiation may not be known. For these reasons, we need research about the factors that influence women's event-level condom-use decisions and behaviors in order to develop effective programs to increase condom use in FTNP encounters.

Because few studies have examined predictors of condom use specifically in FTNP sex, we focus our literature review on what is known about women's condom-use decisions with relatively new or "casual" sex partners. Furthermore, although a broad range of factors has been identified as predictive of heterosexual condom use generally (see Sheeran, Abraham, \& Orbell, 1999, for a meta-analytic review), we focus on two categories of predictors that are particularly relevant to the current study: partner perceptions and alcohol use.

\section{Partner Perceptions}

Young women's typical condom-use habits have been associated with their perceptions of male partners' attitudes toward condom use. There is evidence that young women's expectancies about partners' condom attitudes reduce the effect of their own condom attitudes on the likelihood that they will consistently use condoms (Hogben et al., 2006), particularly among women who are highly sensitive to the possibility of interpersonal rejection (Edwards and Barber, 2010a). These findings suggest that for women who want to use condoms, the belief that their partners do not want to use condoms results in "condominsistence conflict" (i.e., the experience of conflict about whether to insist that a condom be used). Condom-insistence conflict is associated with increased compliance with partners' perceived wishes (Emmers-Sommer, Maier, \& Allen, 2014; Woolf \& Maisto, 2008). These findings are of concern because there is also evidence that young women in casual sexual partnerships tend to underestimate male partners' desire to use condoms (Edwards \& Barber, $2010 b$ ); that is, women may go forward with unprotected sex because they inaccurately believe that their partners do not want to use condoms.

Recent research has explored how event-level partner perceptions influence the likelihood of condom-decision abdication, defined as allowing one's partner to decide whether a condom is used. George et al. (2016) randomized a community sample of young women aged 21-30 to consume alcohol or a placebo beverage and instructed them to imagine themselves in a detailed hypothetical sexual scenario involving a male partner whom the protagonist had been dating for two months. While participants read the scenario, they rated the likelihood that the male partner in the scenario would react negatively (e.g., lose interest or become angry) if they refused to have sex without a condom; they also rated the likelihood that they themselves would abdicate the condom decision (i.e., let the male partner decide whether to use a condom). Greater anticipated negative reactions were associated with a higher likelihood of abdication, particularly for women who had consumed alcohol. A methodologically similar study found that abdication likelihood was positively associated with the likelihood of unprotected sex (Masters et al., 2014). There is little evidence, however, about women's condom-decision abdication behavior in real-world or FTNP sexual encounters. 


\section{Alcohol Use}

The association between young women's typical alcohol consumption and condom use appears inconsistent (Cooper, 2002). Some studies have found that a woman's typical quantity of alcohol consumed per drinking occasion predicted lower rates of condom use (e.g., Walsh et al., 2013), while others have found no association between typical drinking and condom use (e.g., Abbey et al., 2007; Certain et al., 2009). Women's event-level drinking and condom use have also been inconsistently associated (e.g., Leigh et al., 2008; Kiene et al., 2009). In a meta-analysis of event-level associations between alcohol consumption and condom use, Leigh (2002) found that drinking predicted lower condom use only among adolescents; Leigh attributed this effect to the over-representation of sexual debut experiences in adolescent samples. There was no association between drinking and condom use for adults, and Leigh concluded, “.... general [health education] message that alcohol leads to sexual risk behavior is misleading” (p. 481). Offering a more nuanced view of these associations, Parks and colleagues (2011) found that the association between young women's event-level drinking and condom use was moderated by the degree to which they believed that alcohol would enhance sex: Alcohol consumption increased the likelihood of unprotected sex with a casual partner for those with greater enhancement expectancies. Thus, the association between women's alcohol consumption and condom use with new partners appears to be complex and moderated by a variety of situational and person-level characteristics.

Alcohol myopia theory (Steele \& Josephs, 1990) offers a framework for understanding these complex associations. Women enter sexual situations with beliefs and intentions about the need for condom use. In the absence of alcohol intoxication, risky sexual situations may provoke inhibition conflict, in which immediate instigatory cues favoring unprotected sex (e.g., the expectation that sex will feel better without a condom) co-occur with distal inhibiting cognitions about factors that might discourage it (e.g., risk for contracting an STI). Immediate instigatory cues may be pleasure-related, but they also may be partner-related if a woman believes her partner does not want to use a condom or if he expresses resistance to using a condom, which in turn may result in conflict about whether to insist on condom use. When a woman is intoxicated, however, alcohol myopia attenuates focus on distal inhibiting cognitions, such as STI risk, in favor of proximal instigatory cues, reducing inhibition conflict and increasing the likelihood of unprotected sex (Cooper, 2002; Davis, Hendershot, George, Norris, \& Heiman, 2007). Of course, if women do not enter a sexual encounter with the expectation that sex will feel better without a condom, and if they do not experience other instigatory cues such as pressure from a partner, inhibition conflict will not occur regardless of alcohol intoxication, which may explain some of the inconsistent associations between alcohol intoxication and condom use in the literature. Few studies have examined these cognitive mediational processes in the context of sexual encounters with new partners, but the limited evidence (Cooper \& Orcutt, 1997; Dermen \& Cooper, 2000) supports the theoretical framework of the current study. 


\section{The Present Study}

It is clear that knowledge gaps remain regarding how young women make condom-use decisions in risky sexual encounters, especially when having sex with a new partner for the first time. Furthermore, prior research suggests that perceptions about partners' attitudes toward condoms may have an important influence on women's condom-use decisions with new partners, particularly when there is a perceived discrepancy between women's own wishes about condom use and their partners' wishes. Finally, although there are inconsistent findings regarding alcohol's event-level effects on condom-use decisions, alcohol myopia theory presents a promising inhibition conflict-reduction framework for understanding these inconsistent effects.

In the present study, we aimed to address these gaps by examining young women's condomdecision abdication and actual condom use during FTNP sex events, as a function of situational alcohol intoxication, desire to use a condom, perception of partner's desire to use a condom, and conflict about whether to insist on condom use. Figure 1 illustrates our conceptual model. We hypothesized a moderated-mediation model in which the woman's desire to use a condom, and her perception of her partner's desire to use a condom, interact to predict condom-insistence conflict, which in turn positively predicts abdication and negatively predicts condom use (Hypothesis 1). Specifically, we expected conflict to be highest when the woman's desire to use a condom was high and she perceived the partner's to be low, and to be lowest when both had a high desire to use a condom, or when the woman's desire to use a condom was low (regardless of perceived partner's desire to use a condom). Furthermore, we hypothesized that alcohol intoxication would act as an additional moderator, attenuating condom-insistence conflict when it would otherwise be high (Hypothesis 2); in other words, greater intoxication would be associated with lower conflict. Finally, we hypothesized that alcohol intoxication would only predict abdication or condom use indirectly, through condom-insistence conflict (Hypothesis 3); that is, consistent with alcohol myopia theory, we expected alcohol's influence on abdication or condom use to be apparent only by way of its attenuation of women's experience of conflict.

\section{Method}

\section{Participants}

Six hundred nineteen women aged 18-30 participated in a longitudinal study (Bryan et al., 2016) in which they were repeatedly surveyed about their alcohol consumption and sexual experiences over the course of one year. The current analysis was a cross-sectional examination of one first-time new-partner (FTNP) sexual experience per participant in the subsample of participants $(n=179)$ who reported consuming alcohol and having consensual vaginal sexual intercourse with a new male partner (i.e., for the first time with that partner) at least once during their year-long participation. For participants who reported more than one such event, we used the first one they reported in our analysis. Eight participants with qualifying events were excluded because they had declined to provide their body weight, precluding the estimation of blood alcohol concentration. General inclusion criteria for study participation were interest in having sex with men, having had sex with men at least once a month on average during the past year, and having engaged in binge drinking (i.e., 
consuming four or more drinks in two hours; National Institute on Alcohol Abuse and Alcoholism, 2004) at least once during the past year. Women who were currently abstaining from alcohol use were excluded, as were those who endorsed symptoms of alcohol use disorder (the latter because there was a laboratory alcohol administration component of the study not relevant to this report).

The mean age at study entry of the participants included in this analysis was 23.1 years ( $S D$ $=3.1)$. The majority $(77.2 \%)$ identified their race as White, and 6.5\% identified as Hispanic/ Latina. Most (72.0\%) were employed full- or part-time and approximately half (49.1\%) were current students. At study entry, there was substantial variability in typical alcohol consumption and condom-use habits. Participants reported that they typically consumed an average of 12.9 standard alcoholic drinks per week $(S D=7.9$; range $1-39)$ with an average of 3.6 drinking days per week $(S D=1.6$; range $=1-7)$ and 3.6 drinks per drinking day ( $S D$ $=1.7$; range 1-11.7). Participants reported that they had used a condom during vaginal sexual intercourse an average of $53.3 \%$ of the time in the past three months; $21.1 \%$ reported that they never used a condom and $16.8 \%$ reported that they always used a condom.

\section{Procedures}

Recruitment was conducted in Seattle, Washington via fliers and online advertisements and via email at the University of Washington. Women aged 18-30 years were invited to participate in a study about alcohol use and social interactions between men and women. Interested women took an online screening survey to determine their eligibility, and eligible women were contacted by telephone to verify their screening survey responses. Data collection took place online and began with a baseline survey containing questions about demographics, background characteristics, typical alcohol consumption, and condom-use habits during the prior 3 months. Subsequently, during months 3, 6, 9, and 12 postenrollment, participants received a series of four consecutive weekly surveys containing detailed questions regarding each consensual sexual experience they had had (if any) during the past week, and their alcohol consumption (if any) on each day in the past week. For purposes of the current analysis, a single consensual FTNP sexual event per participant was selected from the first survey week in which one was reported; regardless of when the FTNP event occurred over the participant's year-long participation, the follow-up survey responses were collected within one week after the event. These follow-up surveys also contained assessments of a variety of other constructs not central to the current analysis to address different study aims, including ongoing sexual victimization experiences (Bryan et al., 2016), pain and satisfaction associated with sex (Neilson, Norris, Bryan, \& Stappenbeck, in press), ongoing depression and anxiety symptoms (Neilson et al., in press), and partners' coercive behaviors to obtain sex (Stappenbeck et al, under review). Gift cards were provided as compensation. Upon completing each survey, participants were emailed a $\$ 15$ or $\$ 20$ gift card code (depending on the survey week, as some surveys were longer due to additional questions asked only once per assessment month). To encourage participants to complete all weekly surveys, ascending bonus payments were given: If a participant completed all four surveys in any given assessment month, she was emailed a bonus gift card code, and bonus payments increased as the participant completed more surveys. Participants who completed every survey over the course of the year earned a total of $\$ 350$ in gift cards. 
Estimated blood alcohol concentration (EBAC)—Peak EBAC was computed using Matthews and Miller's (1979) formula, which takes into account participants' reported number of standard drinks consumed on the day of the sexual encounter, period of time over which alcohol was consumed, and body weight.

Desire to use a condom-The extent to which participants wanted to use a condom during the sexual encounter was modeled as a latent variable with three single-item indicators, each rated on a 0 (not at all) to 4 (a great deal) scale: "How much did you think about using a condom on that occasion?"; "How much did you want to use a condom on that occasion?"; and "How comfortable were you with the idea of not using a condom on that occasion?" (reverse coded). Items showed good internal consistency reliability (Cronbach's $a=.80$ ). Standardized factor loadings were .79, .90, and .67, respectively (all $p s<.001$ ).

Perception of partner's desire to use a condom-The extent to which participants believed that their sexual partner wanted to use a condom during the encounter was modeled as a latent variable with three single-item indicators, each rated on a 0 (not at all) to 4 (a great deal) scale: "How much do you think your partner wanted to use a condom?"; and extent to which they considered "He doesn't mind using a condom" and "He expects us to use a condom" as reasons to use or not use a condom, worded in the present tense to encourage women to recall the thoughts they were having during that particular encounter. Internal consistency reliability was adequate (Cronbach's $a=.71$ ). Standardized factor loadings were $.93, .34$, and .66 , respectively (all $p s<.001$ ).

Condom-insistence conflict-The degree to which participants experienced conflict about whether to insist on condom use during the sexual encounter was modeled as a latent variable (CONFLICT) with three single-item indicators, each with the stem "Rate how much you agree or disagree" ( $0=$ strongly disagree; $4=$ strongly agree $)$ : "I had a hard time deciding whether or not to insist that my partner use a condom"; "I felt undecided about whether or not to insist that my partner use a condom"; and "I felt conflicted about whether or not to insist that my partner use a condom." Internal consistency reliability was excellent (Cronbach's $a=.95$ ). Standardized factor loadings were .94, .93, and .93, respectively (all $p s<.001)$.

Condom-decision abdication-Condom-decision abdication was modeled as a binary observed variable. Participants were asked to indicate whether they had engaged in the following behavior during the sexual encounter: "Let [partner] decide what to do about using a condom" $(0=n o ; 1=$ yes $)$.

Condom use-Condom use was modeled as a binary observed variable. Participants were asked to indicate, "When you had vaginal intercourse, did you use a condom at any time?" $(0=n o ; 1=$ yes $)$. 


\section{Data Analytic Strategy}

Structural equation modeling (SEM) was conducted in Mplus version 7.4 (Muthén \& Muthén, 1998-2015) using maximum likelihood estimation with robust standard errors (MLR estimator), which provides logit regression coefficients for binary dependent variables (in this analysis, condom-decision abdication [variable hereafter called ABDICATION] and condom use [CONDOM]). Alcohol intoxication was modeled as an observed variable ( $E B A C$ ), while constructs measured with multiple indicators (woman's desire to use a condom $[S H E]$, perception of partner's desire to use a condom $[H E]$, and condom-insistence conflict [CONFLICT]) were modeled as latent variables, which offer greater statistical power and accuracy than manifest variables because associations are not attenuated by random measurement error (Kline, 2011; Little, 2013). We tested our hypothesized model, in which alcohol was a moderator of cognitive mediation pathways, by comparing its fit to the data against the fit of two other nested models representing other possible configurations of alcohol effects on abdication and condom use: Alternate Model 1, in which alcohol was a direct predictor of outcomes (i.e., treated neither as a moderator nor an indirect predictor) and Alternate Model 2, in which alcohol intoxication indirectly predicted outcomes via conflict (but was not treated as a moderator). The best-fitting model, based on Akaike Information Criterion (AIC), sample size-adjusted Bayesian Information Criterion (aBIC), and $\log$ likelihood comparisons, was retained (Kline, 2011). Finally, to produce the most parsimonious solution, paths in the retained model that were not significantly different from zero were constrained to equal zero, with the exception of paths that were main-effect components of significant interaction terms. We probed significant interactions and computed conditional indirect effects to examine differences between indirect effects at varying levels of the moderators.

\section{Results}

\section{Preliminary Analyses}

Means, standard deviations, and bivariate correlations of observed variables are shown in Table 1. The mean EBAC was .13 $(S D=.09)$. The majority of participants $(71.3 \%)$ reported that a condom was used during FTNP sex, and a substantial minority (31.0\%) reported that they abdicated the condom decision to their partner. In bivariate correlations, the variables indicating participants' desire to use a condom were negatively associated with condomdecision abdication and positively associated with condom use, whereas variables indicating partners' perceived desire to use a condom were unrelated to abdication and positively related to condom use. The variables indicating condom-insistence conflict were positively associated with abdication and negatively associated with condom use. Abdication and condom use were not significantly associated.

\section{Model Selection}

Scaled likelihood ratio tests, which provide a difference test statistic distributed as chisquare, indicated that Alternate Model 1 ( AIC $=4666.34$, aBIC $=4665.33$, log likelihood $=$ -2292.17), which represented only the direct effects of alcohol on condom use and abdication, and Alternate Model 2 (AIC $=4668.32, \mathrm{aBIC}=4667.28, \log$ likelihood $=$ -2292.16), which added unconditional indirect effects of alcohol, fit the data equally well 
$\left(\chi^{2}(1)=.0003, p=.99\right)$. The hypothesized model $(\mathrm{AIC}=4663.94, \mathrm{aBIC}=4662.85, \log$ likelihood $=-2287.97)$, which included conditional indirect effects, fit the data significantly better than Alternate Model $2\left(\chi^{2}(2)=12.19, p=.002\right)$ and was thus retained as the bestfitting model. Because indices of absolute fit are unavailable for models containing latent variable interactions, to provide an informal estimate of absolute model fit for the final retained model, we computed a model without interaction terms, which showed modest fit, $\chi^{2}(44)=65.12, p=.02 ;$ RMSEA $=.053(90 \%$ CI .021-.079); CFI $=.907 ;$ TLI $=.860$. Relative fit statistics indicated that the addition of interaction terms improved model fit; thus, we inferred that the absolute fit of our final model, while not directly quantifiable, was likely adequate (Mooijaart \& Satorra, 2012; Muthén, 2012). Constraining non-significant paths to zero did not significantly reduce model fit $\left(\chi^{2}(3)=4.85, p=.18\right)$. Alcohol did not have a significant direct effect on condom outcomes in any model; its only significant influence was as a moderator of indirect effects. The final constrained model is shown in Figure 2.

\section{Cognitive Mediation Model}

As predicted (Hypothesis 1), there was a significant interaction between women's desire to use a condom ( $S H E)$ and women's perceptions of their partner's desire to use a condom $(H E)$ predicting condom-insistence conflict (CONFLICT), which in turn significantly positively predicted condom-decision abdication $(A B D I C A T I O N)$ and negatively predicted condom use (CONDOM). Probing of the SHEXHE interaction (Figure 3) revealed that at low levels of $S H E$, CONFLICT was low regardless of $H E$; at mean and high levels of $S H E$, CONFLICT was negatively associated with HE. Conditional indirect effects (Table 2) of $S H E$ on both outcomes via CONFLICT were significant only at low levels of $H E$ : that is, only when women believed their partners did not want to use a condom did CONFLICT mediate the influence of their own desire to use a condom on $A B D I C A T I O N$ (positively) and $C O N D O M$ (negatively).

\section{Moderating Effects of Alcohol Intoxication}

The three-way interaction term $S H E \times H E \times E B A C$ was non-significant and was therefore constrained to equal zero in the final model. Two-way interactions between $S H E$ and $E B A C$ and between $H E$ and $E B A C$, however, significantly predicted CONFLICT. Probing of the $S H E \times E B A C$ interaction (Figure 4) revealed that when $E B A C$ was low, there was a positive association between $S H E$ and $C O N F L I C T$; when $E B A C$ was moderate or high, however, the association between $S H E$ and $C O N F L I C T$ was non-significant. Finally, probing of the $H E \times E B A C$ interaction (Figure 5) revealed that at low and moderate levels of $E B A C$, there was a negative association between $H E$ and CONFLICT; when EBAC was high, however, there was no significant association.

Taken together, these interactions indicate that CONFLICT was consistently highest when $E B A C$ was low. High levels of $E B A C$ appeared to eliminate or weaken the associations between SHE, HE, and CONFLICT. Consistent with Hypothesis 2, conditional indirect effects (Table 2) revealed that the indirect effect of $H E$ on both outcomes via CONFLICT was significant only at low and mean values of $E B A C$, that is, CONFLICT only mediated the influence of perceived partners' desire to use a condom on $A B D I C A T I O N$ (negatively) 
and $C O N D O M$ (positively) at low to moderate levels of intoxication. At high levels of $E B A C$, the mediating effects of CONFLICT were not observed. These findings also support Hypothesis 3, suggesting that alcohol's influence on condom-related outcomes is indirect via cognitive pathways.

\section{Discussion}

The current study investigated the associations among young women's alcohol intoxication, cognitions about condom use, and condom-related behaviors during first-time sexual encounters with a new male partner. A moderated mediation model revealed that when a woman wanted to use a condom and believed her partner did not, she experienced elevated conflict about whether to insist on condom use, which in turn positively predicted condomdecision abdication and negatively predicted condom use. Furthermore, alcohol intoxication attenuated these indirect effects: Only at lower levels of intoxication did conflict mediate the effects of women's desire to use a condom and their perceptions of their partners' desire to use a condom on condom-related behaviors.

These findings underscore the central role of partner-oriented cognitions and perceptions in determining young women's condom-related behaviors, extending previous findings that women's condom-use preferences do not always align with their eventual behavior (Hogben et al., 2006). Although a variety of factors may influence women's own condom preferences (e.g., appraisals of STI/pregnancy risk, beliefs about the efficacy of condoms, tactile sensations associated with condom use), women do not rely exclusively on their own preferences to inform their decisions about their condom-related behavior; they also take into account how they believe their partners feel. One explanation may be that when women believe that their condom-use preferences do not match their partners', they appraise condom assertiveness or insistence as threatening to the future of the relationship, anticipating, for example, that the partner will become angry and terminate the interaction and/or reject future interactions (George et al., 2016). Women must weigh that threat against the risks of unprotected sex, resulting in conflict about what action to take; conflict, in turn, may increase the likelihood of abdication or decrease the likelihood of condom use.

It is notable that we found no significant association between condom-decision abdication and condom use, particularly because abdication intentions in laboratory research using fictional scenarios have been positively associated with unprotected sex intentions (Masters et al., 2014). In the present study, when women believed their partners did not want to use a condom and abdicated the decision, sometimes a condom was used anyway, suggesting that women's perceptions of their partners' wishes were inaccurate at times. This finding underscores the complexity of the abdication construct, which deserves further study. Although it does not always result in unprotected sex, condom-decision abdication is a risky behavior in that it removes the woman's self-advocacy from the condom-decision process and places decision-making power in the hands of a partner, whose condom wishes may be unknown or contrary to hers.

Alcohol intoxication did not directly predict condom-related behaviors or condom-insistence conflict, but it did act as a moderator: Less intoxicated women experienced greater conflict 
the more they wanted to use a condom and the less they perceived their partners did, but more highly intoxicated women did not experience different levels of conflict depending on their desire to use a condom or perception of their partners' desire to use a condom. This finding may help explain inconsistencies in prior research regarding the links between alcohol intoxication and condom use; most studies have not assessed women's event-level cognitions about partners' desire to use a condom, yet the effect of these perceptions on behavior may vary substantially with intoxication. Unexpectedly, the three-way interaction between women's desire to use a condom, perceived partners' desire to use a condom, and women's alcohol intoxication was not significant. Monte Carlo power analysis indicated that although our sample size was modest, there was sufficient power $(1-\beta=0.89)$ to detect a small standardized effect size $(d=0.3)$ for the three-way interaction, suggesting low probability of a Type II error. Alcohol myopia theory and our interpretations of significant two-way interactions each suggest that the three-way interaction should have been present; it is possible that the absence of this effect was due to an idiosyncrasy in our data, such as characteristics of our sample or measurement error due to retrospection. Further study is needed to fully understand the interplay between these variables.

\section{Theoretical Implications}

Our findings suggest that alcohol intoxication reduces the influence of inhibitory cues on behavior in favor of immediate instigatory cues. While this is consistent with the inhibitionconflict model of alcohol myopia theory, the non-significant three-way interaction between desire to use a condom, perceived partners' desire to use a condom, and alcohol intoxication suggests that conflict results from factors beyond simply a perceived mismatch in condom wishes. In FTNP sex situations, strong instigatory cues, such as sexual arousal and excitement, are likely to be highly salient, and in some cases may produce more conflict about condom use than cues related to partner perceptions. Regardless of the source of conflict (i.e., the specific type of instigatory cue), an intoxicated woman's focus may be directed away from competing inhibitory cues about the risks of unprotected sex, reducing the potential for conflict. In some cases, this may mean that women who would typically be inclined to favor condom use are less likely to advocate for it when intoxicated because they are focused on the pleasurable aspects of the situation or on appeasing their partner's wishes, rather than on the possible risks of unprotected sex. In other cases, the disinhibition associated with alcohol intoxication may be protective: When conflict is reduced, women who strongly want to use a condom are more likely to advocate for condom use, regardless of whether they perceive these wishes to be in conflict with their partners' wishes.

Alternately, it is possible that FTNP sexual encounters that involve greater intoxication produce less conflict simply because they are, on average, more "casual" in nature and less appraised as indicative of future relationship potential; thus, a partner's potential negative response to condom insistence may not be as threatening to relationship goals (Umphrey \& Sherblom, 2007).

\section{Practice Implications}

This study suggests that contextual factors, including alcohol intoxication, influence women's assertiveness with new partners about their condom wishes. Certainly, we do not take our findings to indicate that women engaging in FTNP sex are safer if they are 
intoxicated. The apparently protective effects of disinhibition, however, suggest the importance of teaching young women to prioritize direct, assertive communication with partners about their condom wishes. Although a great deal of emphasis has been placed on obtaining consent for sex (e.g., the recent movement on college campuses encouraging affirmative sexual consent), less has been said about the importance of explicit communication about safer sex practices as a component of consent. Programs aimed at improving consent-related communication among young men and women should include messages about explicit agreement on condom use, particularly since there is evidence to suggest that both sexual assertiveness (Zamboni, Crawford, \& Williams, 2000) and intentional development of condom-supportive norms in one's partner (DiClemente \& Wingood, 1995) predict higher likelihood of condom use.

A strength of this study was its focus on FTNP sex events, which are more likely than other sexual encounters to involve a full decision-making process regarding condom use (as opposed to "default" behavior based on intra-relationship condom norms established during previous sexual encounters with the same partner; de Visser \& Smith, 2001). Condom decisions in FTNP sex are consequential to the extent that they set a precedent for any subsequent sexual encounters with that partner; women may be reluctant, for example, to insist on condom use in a second encounter if a condom was not used during the first (Jacques-Tiura et al., 2015). Thus, although FTNP sex represents a minority of all sexual experiences, it is a potentially potent target for education aimed at increasing young women's assertive behaviors around condom use, and for establishing a habit of condom use for future encounters with a given partner. That said, decision-making processes may differ in non-FTNP situations for a variety of reasons; for example, women may be able to more accurately/confidently assess partners' attitudes toward condoms and STI risk status with regular sexual partners whom they know well.

\section{Limitations and Future Directions}

Several limitations should inform future research in this area. First, because few women in our sample reported more than one FTNP event over the year-long course of their participation, we examined only one event per participant, precluding the examination of within-person variations. For example, although we observed a moderating effect of alcohol intoxication between participants, it is possible that women's deviation from their own typical/average alcohol intoxication predicts outcomes differently than does their actual degree of intoxication (Quinn, Stappenbeck, \& Fromme, 2013). This is an important aspect of alcohol's effects that should be examined in future research. Second, because we surveyed only the female member of each partnership, we were unable to assess the accuracy of women's perceptions of how much their partners wanted to use condoms. Women may underestimate partners' desire to use condoms in casual sexual partnerships (Edwards \& Barber, 2010b); at the same time, men often do resist condom use (Davis et al., 2014a, 2014b), so women's perceptions that men do not want to use condoms may be based on their own experiences with prior partners. There is likely a wide range of accuracy in partner perceptions, and it will be important for future studies to survey both members of a partnership to fully understand the impact of these dynamics. 
Our study also had methodological limitations. First, although women were surveyed about sexual encounters within one week after their occurrence, their reports were still retrospective. Retrospection introduces several potential sources of bias into self-reports (Schwarz, 2007); for example, details about the encounter may be forgotten or conflated with those of other recent sexual encounters; post-encounter experiences (e.g., feelings of regret about not using a condom) may influence a woman's memory of how she felt during the encounter; and the degree of alcohol intoxication proximal to the encounter may influence both ability to remember the encounter and post-encounter processing. Future studies would benefit from using event-level assessments more proximal to the sexual encounter to limit the problems associated with retrospection. Second, the use of EBAC as a measure of alcohol intoxication introduces multiple possible sources of error (amount consumed, time frame of consumption, and body weight) that may lead to inaccurate estimates of actual peak EBAC. We also were unable to assess exactly when peak EBAC occurred, relative to the time of sex on that day; thus, it is possible that in some cases, peak EBAC occurred before or after the sexual encounter. Third, as previously noted, the sample size was modest, which can result in low power to detect effects and inflated parameter estimates (Button et al., 2013; Ioannidis, 2005, 2008; Zhang et al., 2013). Fourth, the effects we observed were correlational, were among closely related variables, and were relatively small in size; thus, replication with larger samples is needed to confirm the validity of our findings. Fifth, our sample was homogeneous with respect to race and ethnicity, and we cannot conclude that our findings would generalize to more diverse populations.

This study illuminated important questions that remain to be answered. As yet, we know little about how a broader range of contextual factors or individual differences may influence condom-related decisions with new partners, or about within-person fluctuations in these decision-making processes. In this study, we examined one important situational predictor of condom-related decision-making (alcohol intoxication), yet additional factors such as partner familiarity, partner's intoxication, and other substance use may also be important moderators of the links between condom attitudes, conflict, and behavior. Moreover, although this study suggested that perceptions about a partner's condom wishes influence women's condom-related behaviors, we know little about what women base these perceptions on. For example, to what extent do women infer a partner's condom wishes based on event-specific cues (e.g., the partner verbally resisting condom use) versus generalizations from previous sexual experiences (e.g., the belief that most men do not want to use condoms)? Under what circumstances are these inferences accurate, and how does alcohol intoxication affect women's accuracy in evaluating their partners' attitudes about condom use? These questions have important implications for how best to promote women's condom-related self-advocacy in risky sexual situations. Future research would benefit from longitudinal designs across multiple years to examine women's decision-making processes in different FTNP situations with different partners, which may provide a basis for educating women about identifying higher-risk FTNP situations (i.e., situations that are most likely to result in unprotected FTNP sex) early enough to proactively discuss condom use with their partners and engage in condom-assertive behaviors. 


\section{Conclusions}

Women consider their sexual partners' wishes when making decisions about safer sex practices, even in relatively risky sexual situations such as sex with a new partner. Situational alcohol intoxication may make condom use more or less likely, depending both on women's perceptions of their partners' wishes and on their own wishes about condom use. Our findings suggest that in order to prepare young women to protect themselves against STIs and unintended pregnancies, sex education programs should explicitly address not only safer sex practices and the effects of alcohol on condom-use decision-making, but also prepare young women to respond to experiences of conflict that may arise during sexual encounters.

\section{Acknowledgments}

This research was supported by grant R01AA014512 from the National Institute on Alcohol Abuse and Alcoholism (NIAAA) to Jeanette Norris.

\section{References}

Abbey A, Parkhill MR, Buck PO, Saenz C. Condom use with a casual partner: What distinguishes college students' use when intoxicated? Psychology of Addictive Behaviors. 2007; 21:76-83. DOI: 10.1037/0893-164X.21.1.76 [PubMed: 17385957]

Amaro H. Love, sex, and power: Considering women's realities in HIV prevention. American Psychologist. 1995; 50:437-447. DOI: 10.1037/0003-066X.50.6.437 [PubMed: 7598292]

Bryan AEB, Norris J, Abdallah DA, Stappenbeck CA, Morrison DM, Davis KC, ... Zawacki T. Longitudinal change in women's sexual victimization experiences as a function of alcohol consumption and sexual victimization history: A latent transition analysis. Psychology of Violence. 2016; 6:271-279. DOI: 10.1037/a0039411 [PubMed: 27213101]

Button KS, Ioannidis JPA, Mokrysz C, Nosek BA, Flint J, Robinson ESJ, Munafò MR. Power failure: why small sample size undermines the reliability of neuroscience. Nature Reviews Neuroscience. 2013; 14:365-376. DOI: 10.1038/nrn3475 [PubMed: 23571845]

Centers for Disease Control and Prevention. Condom Effectiveness Fact Sheet for Public Health Personnel. 2013. Retrieved from http://www.cdc.gov/condomeffectiveness/latex.html

Centers for Disease Control and Prevention. Sexually Transmitted Disease Surveillance 2013. Atlanta: U.S. Department of Health and Human Services; 2014. http://www.cdc.gov/std/stats13/surv2013print.pdf

Certain HE, Harahan BJ, Saewyc EM, Fleming MF. Condom use in heavy drinking college students: The importance of always using condoms. Journal of American College Health. 2009; 58:187-194. DOI: 10.1080/07448480903295284 [PubMed: 19959432]

Cooper ML. Alcohol use and risky sexual behavior among college students and youth: Evaluating the evidence. Journal of Studies on Alcohol. 2002; S14:101-117. DOI: 10.15288/jsas.2002.s14.101

Cooper ML, Orcutt HK. Drinking and sexual experience on first dates among adolescents. Journal of Abnormal Psychology. 1997; 106:191-202. DOI: 10.1037//0021-843x.106.2.191 [PubMed: 9131839]

Davis KC, Hendershot CS, George WH, Norris J, Heiman JR. Alcohol's effects on sexual decision making: An integration of alcohol myopia and individual differences. Journal of Studies on Alcohol and Drugs. 2007; 68:843-851. DOI: 10.15288/jsad.2007.68.843 [PubMed: 17960302]

Davis KC, Schraufnagel TJ, Kajumulo KF, Gilmore AK, Norris J, George WH. A qualitative examination of men's condom use attitudes and resistance: "It's just a part of the game". Archives of Sexual Behavior. 2014a; 43:632-643. DOI: 10.1007/s10508-013-0150-9

Davis KC, Stappenbeck CA, Norris J, George WH, Jacques-Tiura AJ, Schraufnagel TJ, Kajumulo KF. Young men's condom use resistance tactics: A latent profile analysis. Journal of Sex Research. 2014b; 51:454-465. DOI: 10.1080/00224499.2013.776660 [PubMed: 23548069] 
de Visser R, Smith A. Relationship between sexual partners influences rates and correlates of condom use. AIDS Education and Prevention. 2001; 13:413-427. DOI: 10.1521/aeap.13.5.413.24146 [PubMed: 11718441]

Dermen KH, Cooper ML. Inhibition conflict and alcohol expectancy as moderators of alcohol's relationship to condom use. Experimental and Clinical Psychopharmacology. 2000; 8:198-206. DOI: 10.1037//1064-1297.8.2.198 [PubMed: 10843303]

DiClemente RJ, Wingood GM. A randomized controlled trial of an HIV sexual risk-reduction intervention for young African-American women. JAMA. 1995; 274:1271-1276. DOI: 10.1001/ jama.1995.03530160023028 [PubMed: 7563531]

Drumright LN, Gorbach PM, Holmes KK. Do people really know their sex partners? Concurrency, knowledge of partner behavior, and sexually transmitted infections within partnerships. Sexually Transmitted Diseases. 2004; 31:437-442. DOI: 10.1097/01.olq.0000129949.30114.37 [PubMed: 15215701]

Edwards GL, Barber BL. The relationship between rejection sensitivity and compliant condom use. Archives of Sexual Behavior. 2010a; 39:1381-1388. DOI: 10.1007/s10508-009-9520-8 [PubMed: 19760145]

Edwards GL, Barber BL. Women may underestimate their partners' desires to use condoms: Possible implications for behaviour. Journal of Sex Research. 2010b; 47:59-65. DOI: 10.1080/00224490902867863 [PubMed: 19343571]

Emmers-Sommer, T., Maier, MA., Allen, M. Condom use and conflict in heterosexual relationships. In: Burrell, NA.Allen, M.Gayle, BM., Preiss, RW., editors. Managing interpersonal conflict: Advances through meta-analysis. New York, NY: Routledge; 2014.

George WH, Davis KC, Masters TN, Kajumulo KF, Stappenbeck CA, Norris J, ... Staples JM. Partner pressure, victimization history, and alcohol: Women's condom-decision abdication mediated by mood and anticipated negative partner reaction. AIDS and Behavior. 2016; 20:134-146. DOI: 10.1007/s10461-015-1154-3

George WH, Stoner SA. Understanding acute alcohol effects on sexual behavior. Annual Review of Sex Research. 2000; 11:92-124. DOI: 10.1080/10532528.2000.10559785

Harvey SM, Beckman LJ, Gerend MA, Thorburn Bird S, Posner S, Huszti HC, Galavotti C. A conceptual model of women's condom use intentions: Integrating intrapersonal and relationship factors. AIDS Care: Psychological and Socio-medical Aspects of AIDS/HIV. 2006; 18:698-709. DOI: 10.1080/13548500500294435

Hock-Long L, Henry-Moss D, Carter M, Hatfield-Timajchy K, Erickson P, Cassidy A, ... Chittams J. Condom use with serious and casual heterosexual partners: Findings from a community venuebased survey of young adults. AIDS and Behavior. 2013; 17:900-913. DOI: 10.1007/ s10461-012-0177-2 [PubMed: 22460225]

Hogben M, Liddon N, Pierce A, Sawyer M, Papp JR, ... Koumans EH. Incorporating adolescent females' perceptions of their partners' attitudes toward condoms into a model of female adolescent condom use. Psychology, Health \& Medicine. 2006; 11:449-460. DOI: 10.1080/13548500500463964

Ioannidis JP. Why most published research findings are false. PLoS Medicine. 2005; 2:e124.doi: 10.1371/journal.pmed.0020124 [PubMed: 16060722]

Ioannidis JPA. Why most discovered true associations are inflated. Epidemiology. 2008; 19:640-648. DOI: 10.1097/EDE.0b013e31818131e7 [PubMed: 18633328]

Jacques-Tiura AJ, Norris J, Kiekel PA, Davis KC, Zawacki T, Morrison DM, ... Abdallah DA. Influences of acute alcohol consumption, sexual precedence, and relationship motivation on women's relationship and sex appraisals and unprotected sex intentions. Journal of Social and Personal Relationships. 2015; 32:197-221. DOI: 10.1177/0265407514528101 [PubMed: 25755302]

Kiene SM, Barta WD, Tennen H, Armeli S. Alcohol, helping young adults to have unprotected sex with casual partners: Findings from a daily diary study of alcohol use and sexual behavior. Journal of Adolescent Health. 2009; 44:73-80. DOI: 10.1016/j.jadohealth.2008.05.008 [PubMed: 19101461] 
Kline, RB. Principles and practice of structural equation modeling. 3. New York, NY: The Guilford Press; 2011.

Leigh BC. Alcohol and condom use: A meta-analysis of event-level studies. Sexually Transmitted Diseases. 2002; 29:476-482. DOI: 10.1097/00007435-200208000-00008 [PubMed: 12172533]

Leigh BC, Vanslyke JG, Hoppe JM, Rainey DT, Morrison DM, Gillmore MR. Drinking and condom use: Results from an event-based daily diary. AIDS and Behavior. 2008; 12:104-112. DOI: 10.1007/s10461-007-9216-9 [PubMed: 17333311]

Lenoir CD, Adler NE, Borzekowski DLG, Tschann JM, Ellen JM. What you don't know can hurt you: Perceptions of sex-partner concurrency and partner-reported behavior. Journal of Adolescent Health. 2006; 3:179-185. DOI: 10.1016/j.jadohealth.2005.01.012

Little, TD. Longitudinal structural equation modeling. New York, NY: The Guilford Press; 2013.

Masters NT, George WH, Davis KC, Norris J, Heiman JR, Jacques-Tiura AJ, ... Stappenbeck CA. Women's unprotected sex intentions: Roles of sexual victimization, intoxication, and partner perception. The Journal of Sex Research. 2014; 51:586-598. DOI: 10.1080/00224499.2012.763086 [PubMed: 23718552]

Matthews DB, Miller WR. Estimating blood alcohol concentration: Two computer programs and their applications in therapy and research. Addictive Behaviors. 1979; 4:55-60. DOI: 10.1016/0306-4603(79)90021-2 [PubMed: 420046]

Mooijaart A, Satorra A. Moment testing for interaction terms in structural equation modeling. Psychometrika. 2012; 77:65-84. DOI: 10.1007/s11336-011-9232-6

Muthén, B. Latent variable interactions. Mplus webnote. 2012. retrieved from https:// www.statmodel.com/download/LV\%20Interaction.pdf

Muthén, LK., Muthén, BO. Mplus User’s Guide. 7. Los Angeles, CA: Muthén \& Muthén; 1998-2015.

National Institute on Alcohol Abuse and Alcoholism. NIAAA council approves definition of binge drinking. NIAAA Newsletter. 2004 Winter. Retrieved from: http://pubs.niaaa.nih.gov/publications/ Newsletter/winter2004/Newsletter_Number3.pdf

Neilson EC, Norris J, Bryan AEB, Stappenbeck CA. Sexual assault severity and depressive symptoms as longitudinal predictors of the quality of women's sexual experiences. Journal of Sex \& Marital Therapy. 2016 advance online print.

Nesoff ED, Dunkle K, Lang D. The impact of condom use negotiation self-efficacy and partnership patterns on consistent condom use among college-educated women. Health Education \& Behavior. 2016; 43:61-67. DOI: 10.1177/1090198115596168 [PubMed: 26194206]

Niccolai LM, Ethier KA, Kershaw TS, Lewis JB, Meade CS, Ickovics JR. New sex partner acquisition and sexually transmitted disease risk among adolescent females. Journal of Adolescent Health. 2004; 34:216-223. DOI: 10.1016/S1054-139X(03)00250-7 [PubMed: 14967345]

Norris J, Kiekel PA, Morrison DM, Davis KC, George WH, Zawacki T, Abdallah DA, Jacques-Tiura AJ, Stappenbeck CA. How do alcohol and relationship type affect women's risk judgment of partners with differing risk histories? Psychology of Women Quarterly. 2013; 3:209-223. DOI: $10.1177 / 0361684313481763$

Norris J, Stoner SA, Hessler DM, Zawacki TM, George WH, Morrison DM, Davis KC. Cognitive mediation of alcohol's effects on women's in-the-moment sexual decision making. Health Psychology. 2009; 28:20-28. DOI: 10.1037/a0012649 [PubMed: 19210014]

Parks KA, Hsieh YP, Collins RL, Levonyan-Radloff K. Daily assessment of alcohol consumption and condom use with known and casual partners among young female bar drinkers. AIDS and Behavior. 2011; 15:1332-1341. DOI: 10.1007/s10461-010-9829-2 [PubMed: 20949313]

Quinn PD, Stappenbeck CA, Fromme K. An event-level examination of sex differences and subjective intoxication in alcohol-related aggression. Experimental and Clinical Psychopharmacology. 2013; 21:93-102. DOI: 10.1037/a0031552 [PubMed: 23421356]

Reece M, Herbenick D, Schick V, Sanders SA, Dodge B, Fortenberry JD. Condom use rates in a national probability sample of males and females ages 14 to 94 in the United States. The Journal of Sexual Medicine. 2010; 7:266-276. DOI: 10.1111/j.1743-6109.2010.02017.x [PubMed: 21029384]

Rhodes SD, McCoy T, Omli MR, Cohen G, Champion H, Durant RH. Who really uses condoms? Findings from a large internet-recruited random sample of unmarried heterosexual college students 
in the southeastern United States. Journal of HIV/AIDS Prevention in Children \& Youth. 2007; 7:9-27. DOI: 10.1300/j499v07n02_02

Sanders SA, Reece M, Herbenick D, Schick V, Dodge B, Fortenberry JD. Condom use during most recent vaginal intercourse event among a probability sample of adults in the United States. The Journal of Sexual Medicine. 2010; 7:362-373. DOI: 10.1111/j.1743-6109.2010.02011.x [PubMed: 21029391]

Schwarz, N. Retrospective and concurrent self-reports: The rationale for real-time data capture. In: Stone, A.Shiffman, SS.Atienza, A., Nebeling, L., editors. The science of real-time data capture: Self-reports in health research. New York: Oxford University Press; 2007. p. 11-26.

Sheeran P, Abraham C, Orbell S. Psychosocial correlates of heterosexual condom use: A metaanalysis. Psychological Bulletin. 1999; 125:90-132. DOI: 10.1037//0033-2909.125.1.90 [PubMed: 9990846]

Steele CM, Josephs RA. Alcohol myopia: Its prized and dangerous effects. American Psychologist. 1990; 45:921-933. DOI: 10.1037/0003-066X.45.8.921 [PubMed: 2221564]

Umphrey L, Sherblom J. Relational commitment and threats to relationship maintenance goals: Influences on condom use. Journal of American College Health. 2007; 56:61-67. DOI: 10.3200/ JACH.56.1.61-68 [PubMed: 17711828]

Walsh JL, Fielder RL, Carey KB, Carey MP. Changes in women's condom use over the first year of college. Journal of Sex Research. 2013; 50:128-138. DOI: 10.1080/00224499.2011.642024 [PubMed: 22235757]

Winer RL, Lee SK, Hughes JP, Adam DE, Kiviat NB, Koutsky LA. Genital human papillomavirus infection: Incidence and risk factors in a cohort of female university students. American Journal of Epidemiology. 2003; 157:218-226. DOI: 10.1093/aje/kwf180 [PubMed: 12543621]

Woolf SE, Maisto SA. Gender differences in condom use behavior? The role of power and partnertype. Sex Roles. 2008; 58:689-701. DOI: 10.1007/s11199-007-9381-3

Zamboni BD, Crawford I, Williams PG. Examining communication and assertiveness as predictors of condom use: Implications for HIV prevention. AIDS Education and Prevention. 2000; 12:492504. [PubMed: 11220502]

Zhang Z, Xu X, Ni H. Small studies may overestimate the effect sizes in critical care meta-analyses: a meta-epidemiological study. Critical Care. 2013; 17:R2.doi: 10.1186/cc11919 [PubMed: 23302257] 


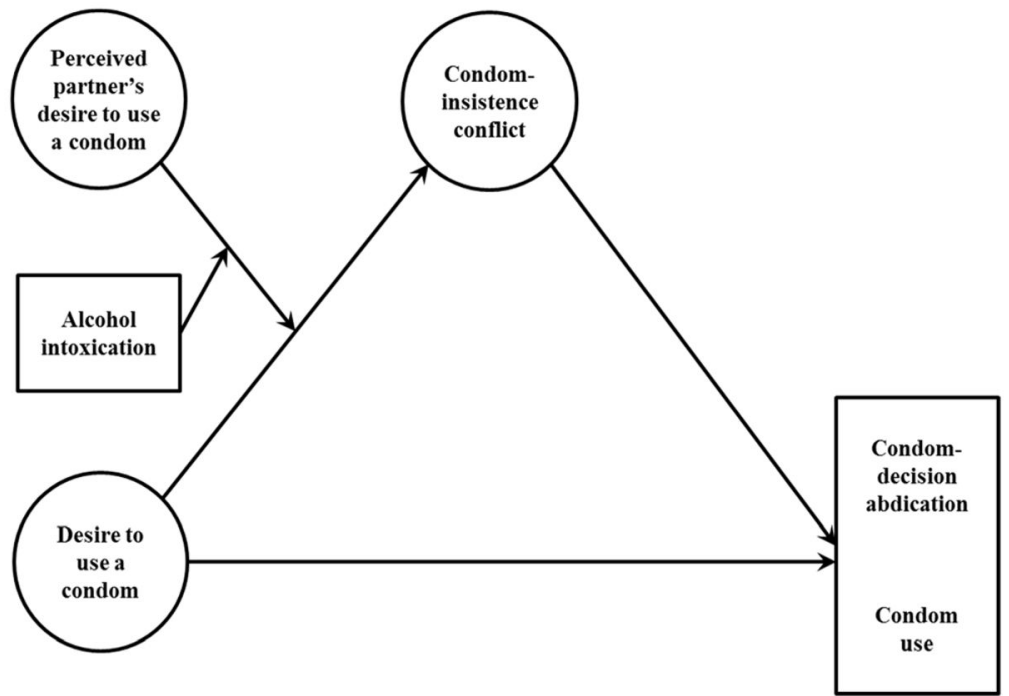

Figure 1.

Illustration of hypothesized conceptual model. The influence of alcohol on outcomes is seen by way of its moderating effect on the interaction between desire to use a condom and perceived partner's desire to use a condom. 


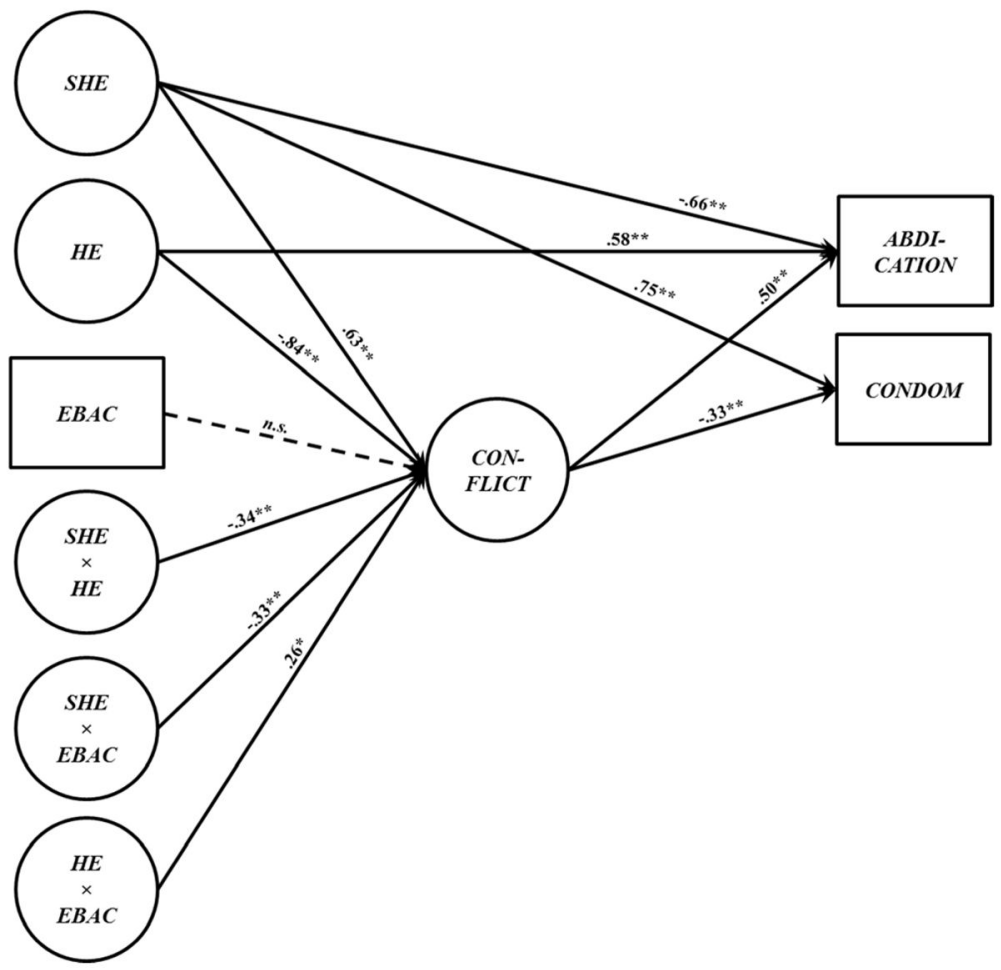

Figure 2.

Final moderated mediation model.

Note. $S H E=$ female participants' desire to use a condom; $H E=$ perceived partners' desire to use a condom; $E B A C=$ estimated blood alcohol concentration; $C O N F L I C T=$ condominsistence conflict; $A B D I C A T I O N=$ condom-decision abdication; $C O N D O M=$ condom use. Estimates shown are standardized. For ease of presentation, observed indicators of latent variables are not shown. 


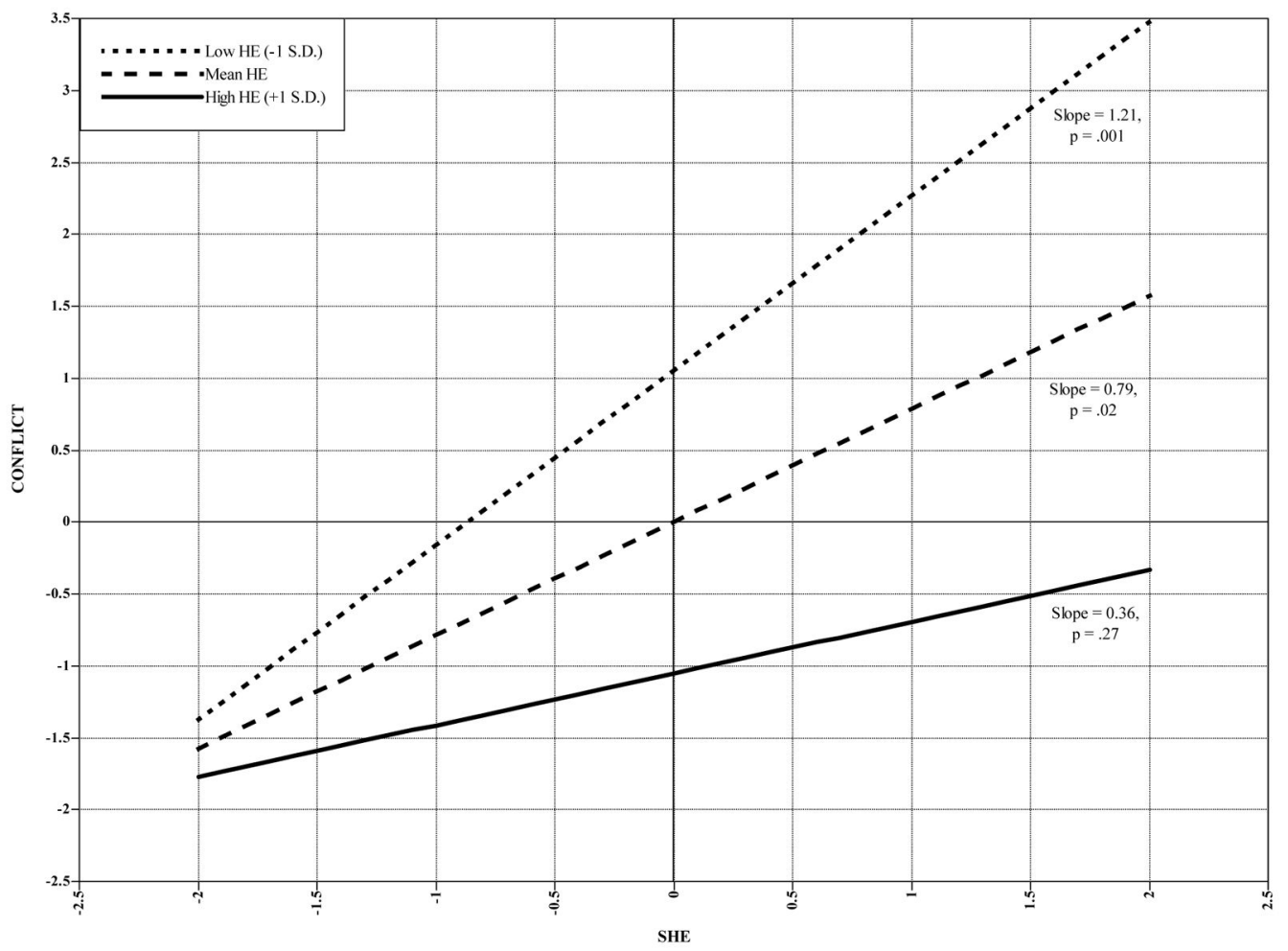

Figure 3.

SHE $\times H E$ interaction 


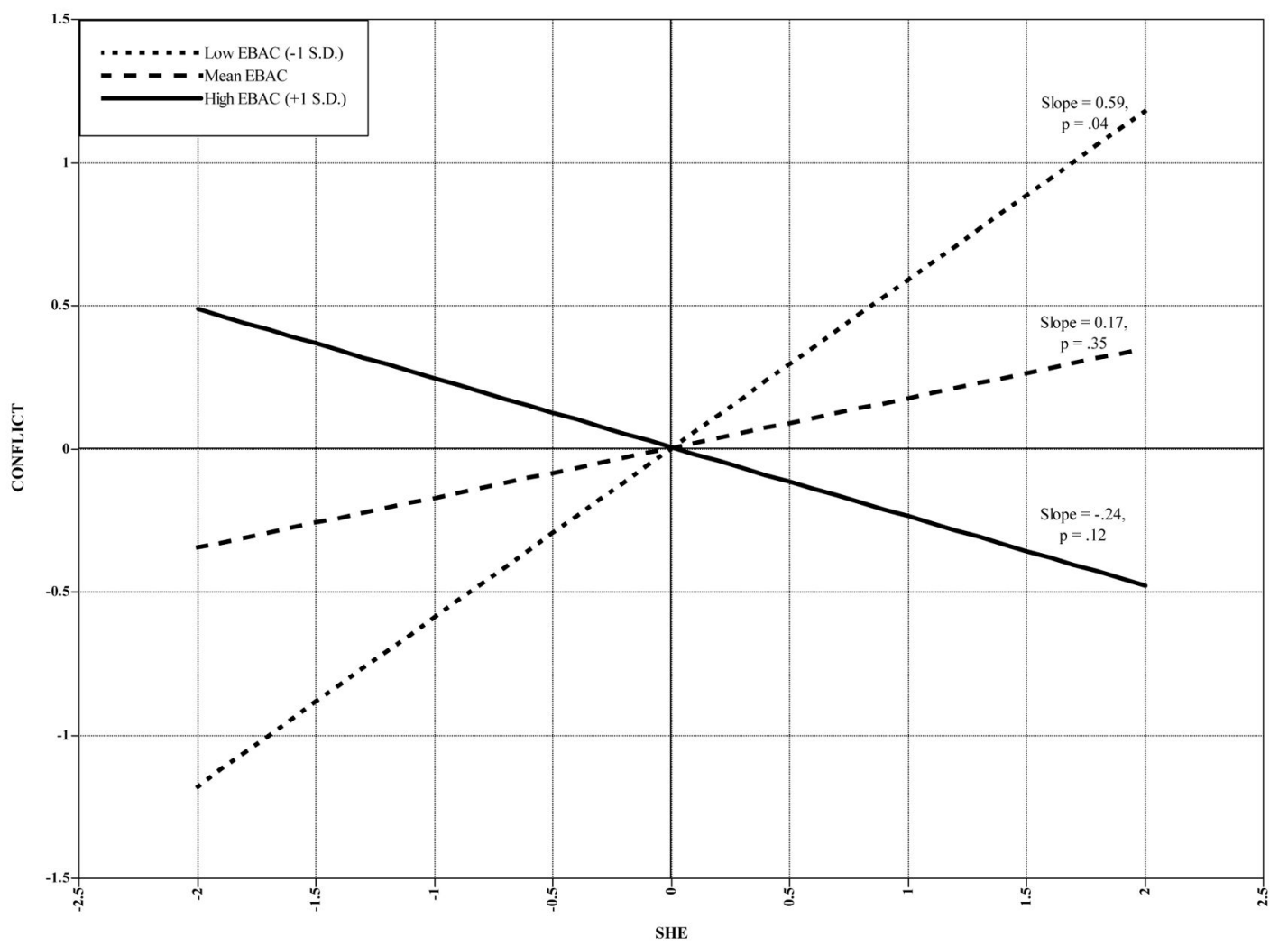

Figure 4.

$S H E \times E B A C$ interaction 


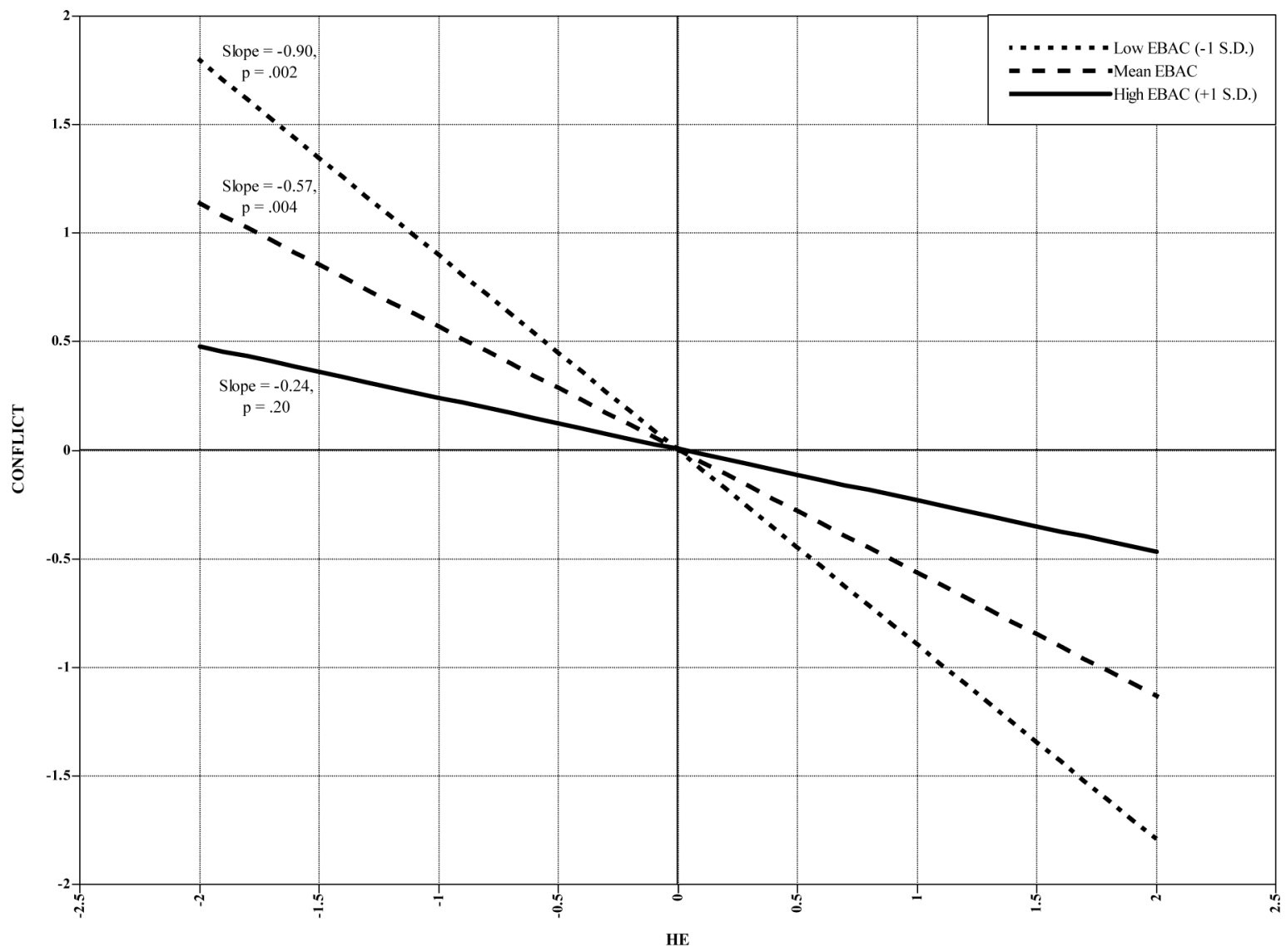

Figure 5.

$H E \times E B A C$ interaction 


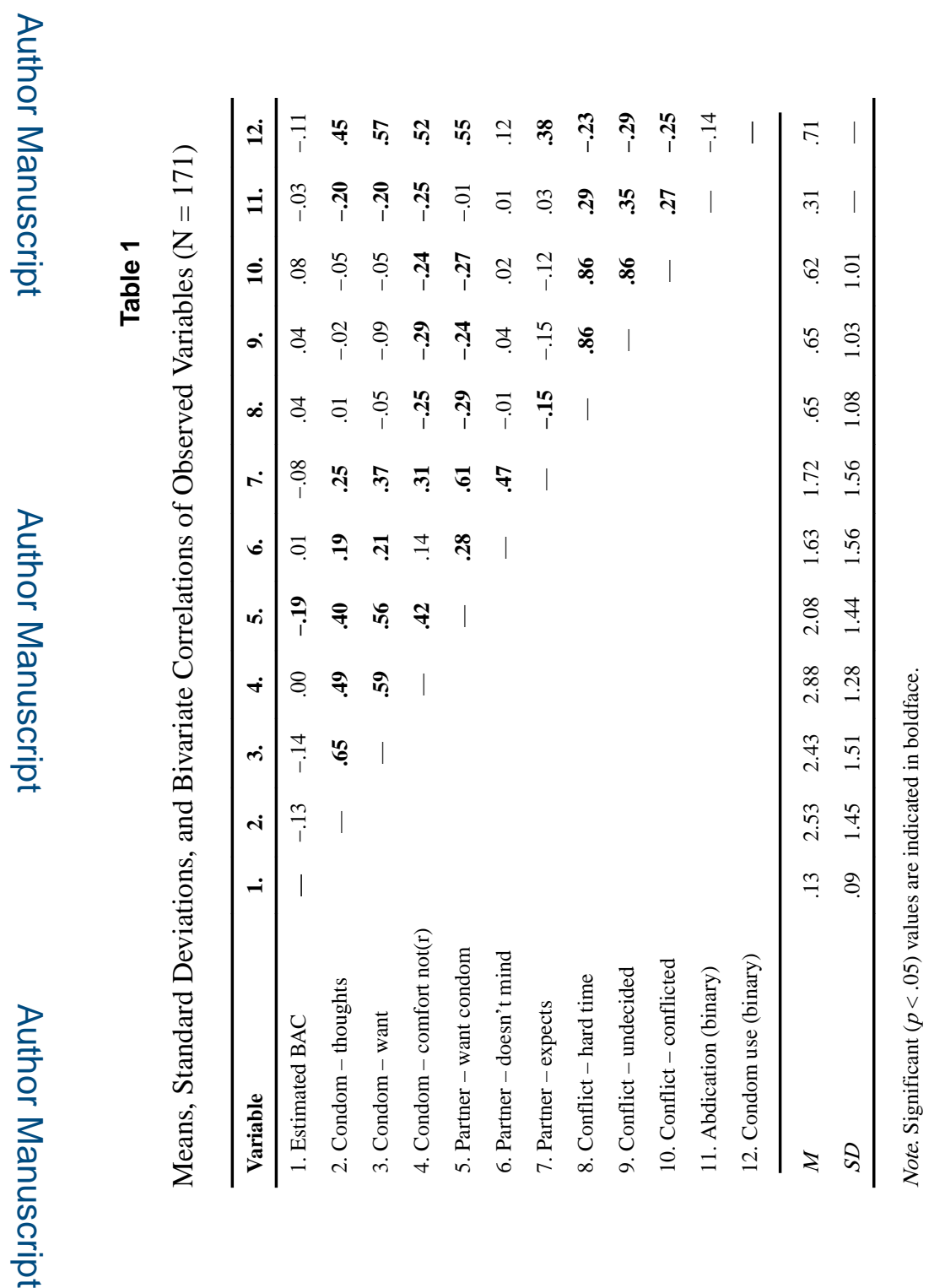

Psychol Women Q. Author manuscript; available in PMC 2018 April 30. 


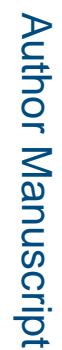

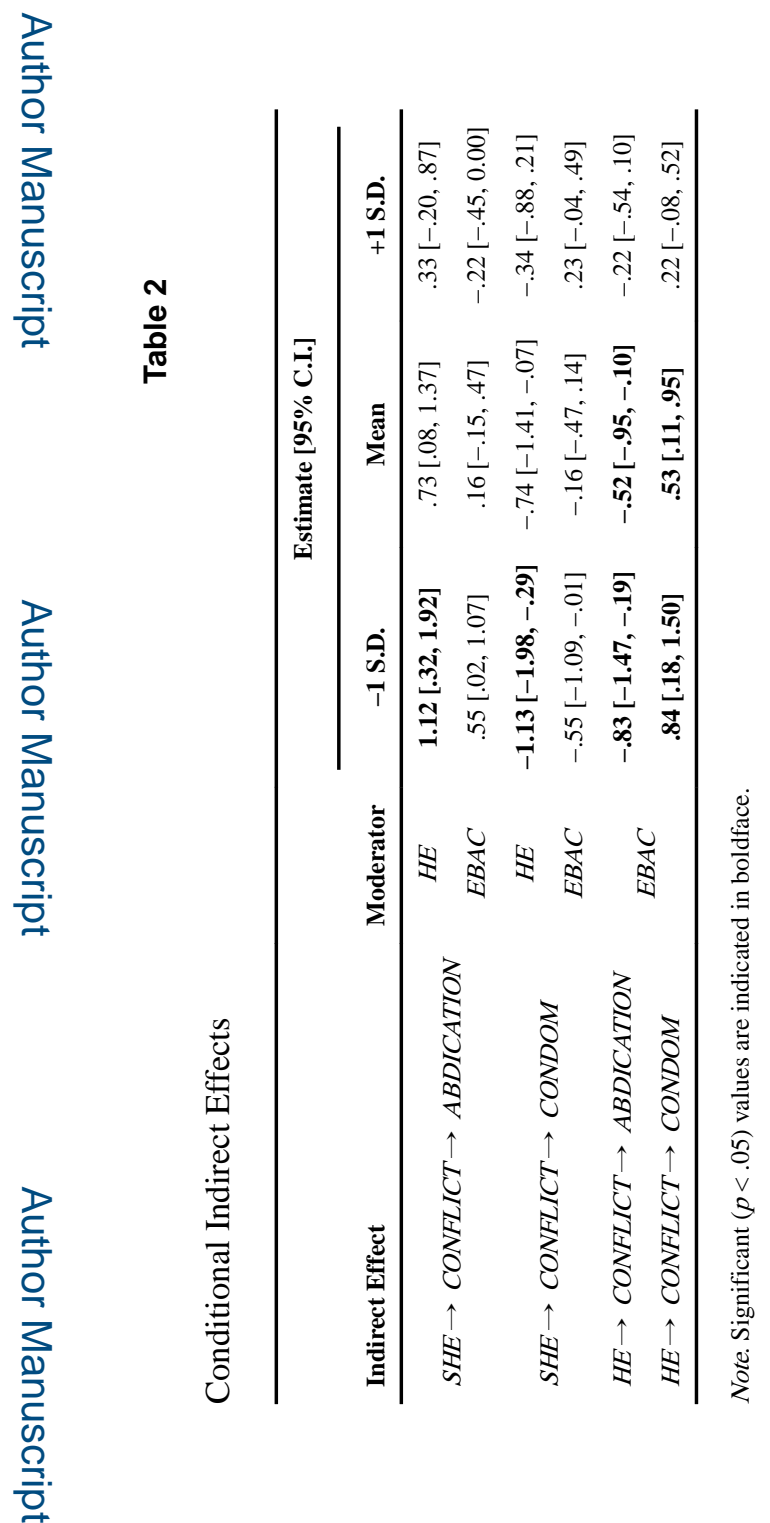

Psychol Women Q. Author manuscript; available in PMC 2018 April 30. 